\title{
Program Evaluation of the English Language Proficiency Program for Foreign Students A Case Study: University of the East, Manila Campus
}

\author{
Esmaeel Ali Salimi ${ }^{1} \&$ Mitra Farsi ${ }^{2}$ \\ ${ }^{1}$ Esmaeel Ali Salimi, Assistant Professor of Applied Linguistics Department of English Language and Literature \\ Allameh Tabataba'i University, Tehran, Iran \\ ${ }^{2} \mathrm{Ph}$. D. Student of of Applied Linguistics, Department of English Language and Literature, Allameh Tabataba'i \\ University, Tehran, Iran \\ Correspondence: Mitra Farsi, Department of English Language and Literature, Allameh Tabataba'i University, \\ Tehran, Iran. E-mail: Farsi_1977@yahoo.com
}

Received: October 23, 2015 Accepted: November 28, 2015 Online Published: December 1, 2015

doi:10.5539/elt.v9n1p12

URL: http://dx.doi.org/10.5539/elt.v9n1p12

\begin{abstract}
This study on evaluating an English program of studies for foreign students seeking admission to the UE Graduate School attempts to examine the prevailing conditions of foreign students in the UE Graduate School with respect to their competence and competitiveness in English proficiency. It looks into the existing English programs of studies in the College of Arts and Sciences and how it addresses the need for an improved academic performance of the foreign students. This study was conducted in the University of the East, Manila campus, particularly in the Graduate School in three groups. All the three groups of respondents have passed the ELPPFS before their admission to UE Graduate School and was enrolled second semester of 2011-2012 in their respective Master and Doctorate courses. Our results show that the three groups of respondents assess that there are significant positive changes in their academic performance as a result of their training in the ELPPFS program. Moreover, there are significant positive changes in the academic performance of the three groups of respondents as a result of their ELPPFS training. The prevailing conditions of foreign students enrolled in degree programs of UE Graduate School with respect to the level of their academic performance clearly show satisfactory evaluation marks.
\end{abstract}

Keywords: English Language Proficiency Program, Stufflebeam's CIPP Model \& Program Theory, program evaluation

\section{Introduction}

The objective of this study is to undertake a program evaluation of the English Language Proficiency Program for Foreign Students, especially for foreign graduate students seeking admission to the UE Graduate School. This study, which uses Daniel Stufflebeam's Context-Input-Process-Product or CIPP Model examined its effects on the academic performance of foreign students. It looked into its course syllabi, goals and objectives, program content, strategies and methodology of instruction, faculty profile and program duration, as these would arrest the competence and competitiveness of foreign students in the English language. In the assessment of foreign students, this study will determine if the English training programs pass William Dunn's four evaluation criteria, namely: effectiveness, responsiveness, appropriateness and adequacy.

In the pursuance of this objective, it seeks answers to the following specific questions:

1) What are the prevailing conditions of foreign students in the UE Graduate School with respect to their academic performance?

2) What are the programs of studies of the ELPPFS to improve their Englis language competencies, in terms of goals and objectives, program content, strategies and methodology used, faculty profile and program duration?

3) In the assessment of the foreign students of the ELPPFS, do these pass Dunn's four criteria of evaluation, namely: effectiveness, responsiveness, appropriateness and adequacy? 
4) Likewise, in the assessment of the foreign students, are there significant positive changes in the level of their academic performance as a result of their training in ELPPFS program?

To date, there is apparently no research conducted to evaluate the existing ELPPFS used by the College of Arts and Sciences for foreign students seeking admission to the UE Graduate School. And so, this study is an attempt to initiate a research on this particular area.

Since the study attempts to make a program evaluation of the ELPPFS with the end to improve their academic performance in the UE Graduate School, the results will have significant implications to the following:

Program Planners - the insights derived in this study can help in their decision making for more effective program management and operations

Educators and Curriculum Planners - the output of this study can help them in their efforts towards professional development in the field of English communication;

Language Program Evaluators - the methodology used in the study could help them evaluate language programs using Dunn's four criteria;

Instructional Materials Developers in all levels-elementary, high school and collegiate;

Classroom teachers in the elementary, secondary and college levels for their daily classroom activities;

The DepEd, CHED, and TESDA in their current thrusts to improve English communication proficiency of their respective constituencies; and

Foreign schools, colleges and universities that are deeply concerned about the academic performance of their foreign students.

This study on evaluating an English program of studies for foreign students seeking admission to the UE Graduate School attempts to examine the prevailing conditions of foreign students in the UE Graduate School with respect to their competence and competitiveness in English proficiency. It looks into the existing English programs of studies in the College of Arts and Sciences and how it addresses the need for an improved academic performance of the foreign students.

Furthermore, in the assessment of foreign students, it seeks to find out if the ELPPFS pass William Dunn's four evaluation criteria, namely: effectiveness, appropriateness, responsiveness and adequacy.

\section{Literature Review}

\subsection{Stufflebeam's Context-Input-Process-Product Model}

The most important contribution to a decision management oriented approach to educational evaluation has been presented by STUFFLEBEAM, DANIEL (2004). His approach is recognized as the context, input, process and product or CIPP model. This comprehensive model considers evaluation as a continuing process. Information is given to the management for the purpose of decision making. It is a three-step process: delineating the information necessary for collection, obtaining the information and providing the information to interested parties. Context evaluation involves studying the environment of the program and the purpose is to define the relevant information, focus on unmet needs and missed opportunities, and diagnose the reasons for unmet needs. It is actually a way to provide information and determine how to utilize resources to meet program goals. It evaluates specific aspects of the program. Process evaluation addresses the implementation decisions that control and manage the program. Product evaluation is the gathering of data to determine the extent the objectives are being attained. It provides evaluators with information that enable them to decide whether to continue, terminate or modify the program. The model can be illustrated in Figure 1 below.

\begin{tabular}{lll}
\hline Aspects of Evaluation & Types of Decisions & Kind of Questions Answered \\
& & \\
\hline Context Evaluation & Planning Decisions & What Should We Do? \\
Input Evaluation & Structuring Decisions & How Should We Do It? \\
Process Evaluation & Implementing Decisions & Are We Doing It as Planned? \\
Product Evaluation & Recycling Decisions & Did It Work?
\end{tabular}

Figure 1. The CIPP (Context-Input-Process-Product) Model of Evaluation 


\subsection{The Program Impact Theory}

The Program Impact Theory has for its proponents Chen, 1990; Lipsey, 2004; Martin and Kettner, 2003.

The program theory is composed of the impact theory and the process theory.

The impact theory is the theory showing the results or outcomes that are supposed to be produced by the program activities. These outcomes include both proximal outcomes (more immediate or direct results) and distal outcomes (more ultimate or longer term outcomes that result from the proximal outcomes). The action theory (or action hypothesis) specifies the expected immediate or proximal outcomes of the program actions; the conceptual theory (or conceptual hypothesis) specifies the expected distal or longer term outcomes.

The next two components of the program theory (service utilization and organizational plan) are known as the program process theory and they require process evaluation.

The service utilization plan is the expectations about how program clients will become engaged with the program and participate in program activities. It describes the program-target transactions (and what is behind those transactions) from the perspective of the program target participants. It explains what the participants must do if they are to be part of the program.

The organizational plan is the expectations about how the program will be organized and maintained. It describes the program-target transactions (and what is behind those transactions) from the perspective of program management. It explains what the organization must do to deliver and maintain an effective program.

There are three interrelated components of the Program Theory and all these components compliment each other. The inputs and activities represent the program organization. The outputs represent the service utilization. The process theory includes both the program organization and the service utilization. Next is the impact theory (labeled Outcomes) which includes the initial outcomes, intermediate outcomes, and the longer term outcomes. These can be illustrated in Figure 2 shown below.
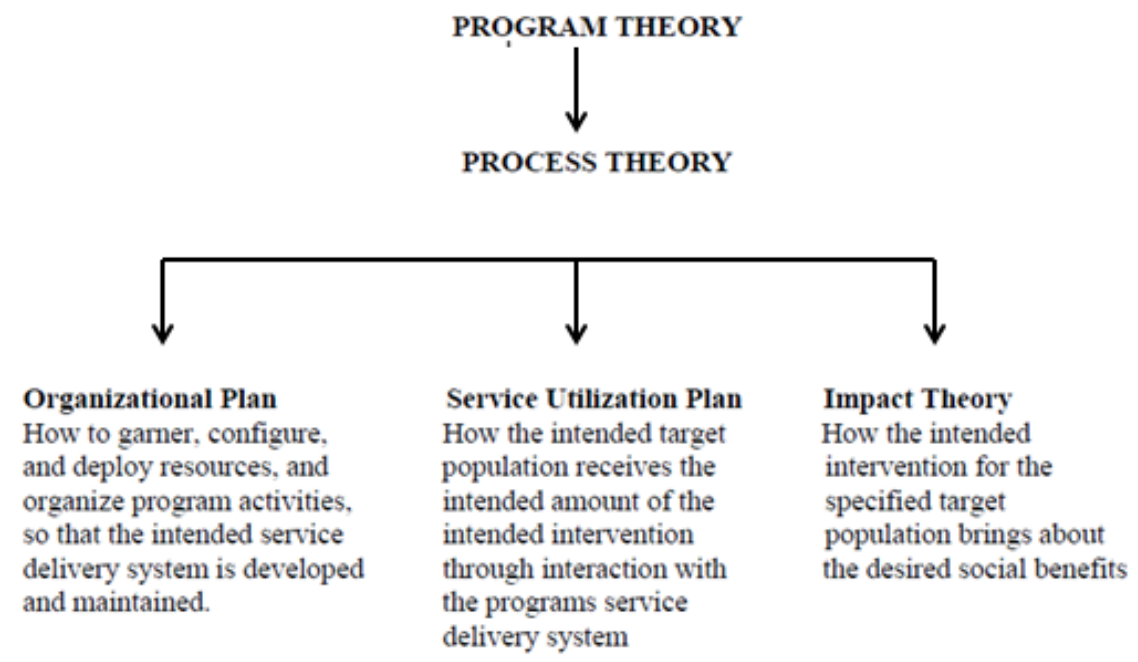

Figure 2. The Program Theory and its Three Components

It should be obvious that there are a lot of things that need to be examined when one is articulating or describing a program theory (CHEN, 2002. In articulating (or describing) a program theory, first, there is a need to come up with a clear definition of the program, its objectives, and its boundaries that are negotiated and agreed upon by the evaluator and the primary stakeholders.

Rutman (1984) defines a program as an intervention or set of activities mounted to achieve external objectives, that is, to meet some recognized social needs, or to solve an identifiable problem. Typically, organizations work from their mission to identify several goals which must be reached to accomplish their mission. What is program evaluation? It is a process of carefully collecting information about a program or some aspects of a program in order to make necessary decisions about the program. 
Program evaluation can include any or a variety of at least 35 different types of evaluation, such as for needs assessments, accreditation, cost/benefit analysis, effectiveness, efficiency, formative, summative, goal based, process, outcomes, and a lot more. The type of evaluation one undertakes to improve his program depends on what he wants to learn about the program. Program evaluators may assess programs on several dimensions to determine whether the program works. Rossi et al. (2004) divide these dimensions into five categories: needs assessment, program theory, process analysis, impact analysis, and cost-benefit \& cost-effectiveness analysis. When an evaluator examines the nature of the problem that the program is meant to address, it is called needs assessment. This would include evaluating who is being affected by the problem, how widespread the problem is, and what effects stem from the problem. The program theory is the formal description of a program's concept and design. The program theory breaks down the components of the program and shows anticipated short term and long term effects. A real analysis of the program theory examines how the program is organized and how that organization will lead to desired outcomes. It will also reveal unintended or unforeseen consequences of a program, both positive and negative.

The third category is process theory which looks beyond the theory of what the program is supposed to do, and instead evaluates how the program is being implemented. The evaluation determines whether the target population is being reached, people are receiving the intended services, staff are adequately qualified, and many others. The fourth category is impact evaluation which determines the causal effects of the program.

Finally, cost-benefit and cost-effectiveness analysis assesses the efficiency of the program. Evaluators outline the benefits and the cost of the program for comparison. The most difficult part of evaluation is determining whether the program itself is causing observed impacts. Events or activities outside the program may be the real cause of the observed outcome. Causation is difficult to determine. People select themselves to participate in the program. Those who do participate may differ from those who do not in important ways. They may become determined to find a job or have better support resources.

A study titled "The impact of English-language proficiency on international graduate students' perceived academic difficulty", the author, Ming Xu, presents an empirical test of the impact of English proficiency as indicated by student self-ratings and TOEFL scores, and selected nonlinguistic variables on the level of academic difficulties perceived by international graduate students. A simple random sample of 450 international graduate students from three large universities in upstate New York were contacted by mail in the fall of 2008. 245 completed the Survey of International Students" Academic Language Needs. It was found that English Proficiency in ESL programs and school curriculum designs were the most significant predictors of the perceived level of academic difficulty.

In another study conducted by A.A. Winke, and published as a journal article in "Higher Education, 2009" Volume 31, no 3, 325-340, it investigated associations between studying in a foreign English language and students' academic achievement and behaviour. Data were gathered in the Netherlands, at the Delft University of Technology (DUT). The results show that the success rate of foreign students was about the same as that of the Dutch students, but that foreign students needed more time to pass the examination. Language proficiency played a major part in explaining differences in study achievement as did the presence or absence of a selection procedure in the student's country of origin. Furthermore, the results show that the study behaviour of foreign students was significantly different from the Dutch students: their average grades on examinations were lower, they made more attempts before passing an examination, they were more likely to postpone examinations and to follow a different order from the recommended one. Suggested measures to improve foreign students' study success include requiring higher levels of language proficiency and stricter selection of foreign students in the country of origin. It is suggested that a system of mentors which provides for intensive coaching of foreign students in their first year may prevent a slow start.

In the Netherlands, internationalization of higher education led to an increasing use of a foreign language-for example English-as the medium of instruction. This raised the issue whether learning in a foreign language affects academic performance, given the language problems international students are faced with when studying abroad. This article reviews research in this field and presents a study into the academic achievement of 90 Indonesian engineers. These subjects took a one-year English-medium graduate course at the International Institute for Hydraulics and Environmental Engineering in Delft. Language proficiency was measured by TOEFL and academic success was defined as the average score on seven written examinations. A most remarkable finding is the observation of a cut-off point in the relationship between English proficiency and academic success. This has led to the hypothesis that there is a range of TOEFL scores within which a better command of English increases the chance of being academically successful. The lower and upper limits of this range may vary according to academic discipline or may even be institution-specific. This study was published as a journal article: "Career Placement 
Concerns of International Graduate Students: A Qualitative Study" by Yih-Jiun Shen for Higher Education Vol 32, 2008.

In the Philippine context, all member-schools and institutions of Philippine Association of Graduate Education or PAGE strictly rule admission requirements for international students, and set high standards of academic performance of graduate students as part of its thrust for continuing professional education and upgrading. PAGE'S main theme "Dissemination and Utilization of Research Outputs," for its 2011 Annual Assembly was articulated by its keynote speakers, CHED Commissioner Nona Ricafort and Dr. Isagani Cruz who lectured about an impressive academic performance of international students pursuing graduate programs in PAGE schools and institutions over the years.

\section{Research Methodology}

The following null hypotheses are tested in this study:

a. There are no significant positive changes in the assessment of the foreign students as to whether or not their academic performance improved because of the ELPPFS.

b. ELPPFS programs of study as assessed by the three respondent groups did not pass Dunn's four evaluation criteria, namely: effectiveness, responsiveness, appropriateness and adequacy.

This study was conducted in the University of the East, Manila campus, particularly in the Graduate School.

Specially tapped and involved in the study are the following:

1) Group A - Ten (10) Iranian graduate students

2) Group B - Ten (10) Chinese graduate students

3) Group C - Mixed Group of 10 foreign students (Koreans, Taiwanese, Nepalese, Myanmar, Yemen)

All the three groups of respondents have passed the ELPPFS before their admission to UE Graduate School and are currently enrolled this second semester of 2011-2012 in their respective Master and Doctorate courses.

Specifically, these thirty (30) respondents represent the number of returned survey forms taken from a total of sixty (60) fielded in the graduate school.

Cluster sampling is used, that is, the researcher categorizes the respondents in three (3) clusters (i.e. Group A Iranians, Group B - Chinese, and Group C - Mixed Group. Each cluster is represented by ten (10) subject respondents. These three clusters of respondents answered the questionnaire, as well as questions raised in the structured interviews conducted by the researcher.

The research instrument focuses on each criterion of the evaluation framework, namely: effectiveness, responsiveness, appropriateness and adequacy. Each criterion has indicators which the respondent is asked to rate, using Likert's 4-Point Scale: 4 - strongly agree, 3 - agree, 2 - disagree, and 1 - strongly disagree.

The survey questionnaires are validated by a panel of three faculty members from the Graduate School of Our Lady of Fatima University using 3-point criteria, namely: clarity of instruction and language, content and substance of each indicator in the checklist, and clarity and acceptability of format. The three faculty members responded to the questionnaire and their suggestions for improvement used for our instrument.

\section{Findings}

For purposes of clarity and organization, the researcher presents a tabulated presentation of responses to the four criteria, each criterion having a checklist of five indicators as shown in the following statements:

\section{Criterion 1 - EFFECTIVENESS}

The extent to which ELPPFS goals and objectives are achieved

\section{Criterion 1.1}

I believe I have acquired a certain level of English proficiency after completing the ELPPFS course - a good start to improve my communicative competence.

The result shows an averaged half or $50 \%$ of each of the three respondent groups that rate themselves with Agree, and an averaged 30\% with the Strongly Agree mark. Groups A and B post no Strongly Disagree rating except Group C. However, a small percentage in each group rates a Disagree.

Criterion 1.2 
My command of spoken language is now enhanced and enriched because of the many oral drills and activities taught in the training course.

The result shows seven (7) Iranians rate an Agree mark, while only three with Disagree. Similarly, the Chinese respondents have six (6) Agree marks and three (3) Strongly Agree marks, and only one has a Disagree vote. The Mixed Group has three (3) for Strongly Disagree, five (5) for Agree and two (2) for Disagree. None give a Strongly Disagree score.

Criterion 1.3

Gradually, my inhibition to communicate is lessened and replaced by a reasonable degree of confidence and certainty.

The result shows the groups of Iranian and Chinese with $60 \%$ and $70 \%$ mark for Agree, respectively, while Group $\mathrm{C}$ gives an almost balanced distribution of its points. All the three groups have a stock evaluation for Agree mark, and none of them give a Strongly Disagree score.

Criterion 1.4

ELPPFS includes in its program of studies an orientation of the University of the East, its mission-vision statements, and its significance to my life as a foreign graduate student.

The result shows Group A and B each giving a 70\% Agree score. In all three

respondent groups, there is but one Chinese respondent who posts a Strongly Disagree score. Five (5) respondents from the Mixed Group post a Strongly Agree mark. In summary, out of thirty (30) respondents, only three (3) post Disagree scores.

\section{Criterion 1.5}

I realize that ELPPFS improved not only my command of speaking the English language, but also my writing, reading and listening skills.

The result shows two high scores by Group of Iranians giving a 70\%, and the Group of Chinese giving a $90 \%$ for the Agree mark; also, both giving Zero for Strongly Disagree. All three groups post an averaged $15 \%$ for Strongly Agree. The Mixed Group registers 20\% for a Strongly Disagree score.

Criterion 2 - RESPONSIVENESS

The extent to which ELPPFS responds to the special needs of foreign students.

Criterion 2.1

Initially, ELPPFS training prioritized on the special need of foreign students for conversational English, which I personally feel to be a very urgent concern of every foreign graduate.

The result shows high marks of $70 \%$ and $90 \%$ for Agree rating given by Group A and Group B, respectively. The same groups post Zero for Strongly Disagree. While one Iranian respondent from Group A gives a Strongly Agree rating, two respondents from the same group rate 20\% Disagree. From the total of thirty (30) respondents, only six give negative scores.

Criterion 2.2

Instructional materials are carefully chosen to enable foreign students to easily relate their experiences, interests and views, thereby making language learning a truly rewarding and fulfilling event.

The result shows Group A, Group B and Group C giving it 60\%, 70\% and 60\%.marks in Scale 3 or Agree, respectively. No group gives a Strongly Disagree mark. Three respondents from Groups B and C give a Strongly Agree rating.

\section{Criterion 2.3}

The expertise of ELPPFS instructors enables them to identify the strengths and weaknesses of every foreign student, making program content relevant and flexible to match individual abilities of the students.

The result shows Group A and C giving a 60\% rating for Scale 4 or Strongly Agree. While Group B gives Zero to Scale 4, it posts a high 70\% to Scale 3. None from the three groups marks a Strongly Disagree. Seven (7) from the three groups rate a Disagree score. In summary, twenty three (23) respondents are in Agree scales, and only seven (7) in Disagree scales.

Criterion 2.4 
The ELPPFS program of studies regularly administers evaluation activities to monitor the growth and progress of the students, aside from class quizzes and formal examinations.

The result shows Group A of Iranians balancing the scales of Agree and Strongly Agree to that of Disagree and Strongly Disagree. However, all Chinese respondents respond to Strongly Agree with $30 \%$, and to Agree with a high $70 \%$, and no Disagree ratings. Furthermore, the heterogeneous group of Group C clearly shows its varied responses.

\section{Criterion 2.5}

In some special instances, ELPPFS instructors conduct tutorial classes outside the regular class hours, especially for foreign students classified as slow learners.

The result shows varied responses from the three respondent groups. In the case of the Mixed Group, all four scales are marked, especially Scale 3 that is given $40 \%$ rating. The Chinese group evaluates themselves by giving a high $70 \%$ for Agree and a low 30\% for Disagree. The Iranians post no Strongly Disagree but one respondent gives a Strongly Agree, four (4) respondents with Agree ratings and five (5) respondents with Disagree rating.

\section{Criterion 3 - APPROPRIATENESS}

The extent to which the sets of values are integrated and inculcated in

ELPPFS program of studies.

Criterion 3.1

The ELPPFS program of studies, always cognizant of the Vision-Mission statements of the university has succeeded in integrating values in its goals and objectives of instruction.

The result shows a consistent pattern of responses from Group A and Group B. Both groups give a 10\% and $20 \%$ for Scale 4 or Strongly Agree, a $60 \%$ for Scale 3 or Agree, and a 30\% and $20 \%$ for Scale 2 or Disagree. None of the groups mark a Scale 1 or Strongly Disagree. Group C gives a high rating of $70 \%$ for Scale 3 or Agree, and a 30\% for Strongly Agree.

Criterion 3.2

Always, classroom discipline and time management are strictly observed in ELPPFS program of studies.

The result shows the three respondent groups giving a high mark of $60 \%$ (Iranians and Chinese) and $40 \%$ (Mixed Group) for Scale 3 or Agree.

From the thirty (30) respondents, twenty one (21) post Agree scores and only nine (9) with Disagree scores.

Criterion 3.3

Consultation schedules with the instructors are posted at Bulletin Boards of the CAS Building. Consultations are always characterized as cordial and worthwhile.

The result shows a very high $90 \%$ mark of Group B - Chinese respondents, and only one respondent rates a Disagree scale. Group C gives a 40\% for Strongly Disagree, $20 \%$ for Agree, $20 \%$ for Disagree and 20\% for Strongly Disagree. Group A registers a 40\% for both Agree and Disagree scales, and 20\% for Strongly Disagree.

Criterion 3.4

Honor system is always observed by all foreign students in the ELPPFS program of studies, especially during examinations and submission of paper works and other class projects.

The result shows a $60 \%$ rating of Iranians for Scale 2 or Disagree. On the other hand, the Chinese respondents post a $70 \%$ rating for Scale 3 or Agree and only $20 \%$ for Scale 2 or Disagree. From a total of thirty (30) respondents, nineteen (19) are in the Agree scales in varying scores and eleven (11) respondents in Disagree scales.

\section{Criterion 3.5}

Guidance Counseling is an integral part of the ELPPFS program of studies, the purpose of which is to provide student care and counseling to whoever needs it.

The result shows Group B's high 90\% mark for Scale 3 or Agree with only one respondent that marks a Scale 2 or Disagree. Both Groups A and C post a total of $70 \%$ for Agree in varying scales and 30\% for Disagree scales. None of the three groups of respondents give a Zero or Strongly Disagree rating. 


\section{Criterion 4-ADEQUACY}

The extent to which ELPPFS program of studies provides general knowledge, develop English communication skills and foster wholesome attitudes to its foreign students.

Criterion 4.1

The ELPPFS has constantly updated its program content with the latest information technology. I appreciate how foreign students used multi-media presentations and other state-of-the-art presentations as integral part of language learning.

The result shows a recurring pattern of responses from the three respondent groups. Group B gives a $90 \%$ for Scale 3 or Agree, and a $10 \%$ for the Disagree. Group A posts a $40 \%$ for Strongly Agree, and another $40 \%$ for the Disagree scale. Furthermore, the Group C has eight (8) respondents for the Agree scale and only two (2) for the Disagree.

\section{Criterion 4.2}

I like the way ELPPFS manages in making maximum use of class time and resources in language teaching assigning 60 full hours in this course is just fair to meet the course objectives.

The result shows varying responses from the three groups of respondents. Twenty (20) respondents from a total number of thirty (30) respondents post Scale 4 and Scale 3 of Agree. Ten (10) respondents mark Scale 2 and Scale 1. Groups B and C give a Zero score for Strongly Disagree except Group A.

\section{Criterion 4.3}

ELPPFS encourages foreign students to join in extracurricular activities like campus tours. Students participate in some university contests and competitions, particularly along the line of English language.

The result shows Group A and Group B with high marks of $70 \%$ and $80 \%$, respectively, to Scale 3 or Agree. Likewise, the same groups post a $20 \%$ and $30 \%$, respectively, to Scale 4 or Strongly Disagree. Only three from the thirty respondents have dissenting response.

\section{Criterion 4.4}

Furthermore, students are allowed to attend in-campus seminars and workshops that offer supplementary, relevant information and experience in the area of English proficiency.

The result shows a recurring pattern of Group C's varying ratings in all scales of the Likert. This is due to the heterogeneous composition of Group C which distinguishes them from Group A and Group B. The Chinese group gives a 70\% rating for Scale 3, a 10\% rating for Scale 4, and a 20\% rating for Scale 2.

\section{Criterion 4.5}

I believe that ELPPFS has maintained its reputation as one specialty area of scholarly learning in the College of Arts and Sciences of the University of the East, truly committed in providing basic communication skills for the students towards enriched academic performance in the Graduate School.

The result shows a high mark of $90 \%$ Agree rating and 10\% Disagree rating from Group B. On the other hand, Group A and Group C present almost similar ratings in all four scales of the Likert. Twenty three (23) respondents post Agree scales and only seven (7) post Disagree scales.

From the above data, the researcher believes that results indicated confirm the contention that ELPPFS is a specialty area of the English Department and a vital arm of the Graduate School 
Table 1. Summary of results showing the mean and standard deviation of the responses to the four criteria

\begin{tabular}{llllll}
\hline & $\mathrm{C} 1$ & $\mathrm{C} 2$ & $\mathrm{C} 3$ & $\mathrm{C} 4$ & \\
\hline GROUP A & 2.92 & 2.84 & 2.78 & 2.90 & MEAN \\
& 0.36 & 0.50 & 0.50 & 0.54 & STANDARD \\
& & & & & $\begin{array}{l}\text { DEVIATION } \\
\text { GROUP B }\end{array}$ \\
& 3.0 & 2.90 & 2.94 & 2.84 & MEAN \\
& 0.37 & 0.26 & 0.26 & 0.26 & STANDARD \\
GROUP C & 3.06 & 3.02 & 3.10 & 2.92 & MEVIATION \\
& 0.79 & 0.84 & 0.74 & 0.81 & STANDARD \\
& & & & & DEVIATION \\
F-VALUE & 0.49 & 0.79 & 2.55 & 0.16 & \\
P-VALUE & 0.62 & 0.46 & 0.08 & 0.85 & \\
\hline
\end{tabular}

LEGEND: GROUP A - IRANIANS; GROUP B - CHINESE; GROUP C -MIXED GROUP; C1 - Criterion 1: EFFECTIVENESS; C2 - Criterion 2: RESPONSIVENESS; C3 - Criterion 3: APPROPRIATENESS; C4 -Criterion 4: ADEQUACY.

Table 1 shows that using the 10-point Standardized Checklist and the Rating Scale consisting of Scale 4 Much Improved, Scale 3 Improved, Scale 2 Less Improved and Scale 1 Not Improved, the three respondent groups obtain highest marks for Scale 3 -Improved. Ranking second is Scale 2 - Less Improved, followed by Scale 4 - Much Improved. Scale 1 - Not Improved ranks the last. These results identify the fact that from the three respondent groups, it is the Group C or the mixed group that indicates a high level of improved academic performance with a total mean rating of 3.28, while Group B of Chinese students comes second with a total rating of 2.82. Group A or Iranian students have a total mean rating of 2.20 to rank the last.

From the above data, the researcher believes that the three groups of respondents show significant positive changes in their level of academic performance as a result of their training in ELPPFS program, although the Iranians admit that they have experienced less improvement. The same table shows the computed value of 37.66 (or F-ratio) which is greater than the critical value of 5.49 based on a $99 \%$ level of confidence ( 0.01 Alpha). This means that the null hypothesis is rejected because there is sufficient evidence to support the significant changes in the respondents' level of academic performance.

Qualitatively, or on the basis of data collected from the structured interviews and taped conversations, the researcher finds that there are significant changes in the level of academic performance of the three respondent groups as a result of their training course in the ELPPFS.

\section{Discussion and Conclusion}

The objective of this study is to undertake a program evaluation of the English Language Proficiency Program for Foreign Students or ELPPFS, specifically for international students seeking admission to the UE Graduate School. This study, which uses Daniel Stufflebeam's Context-Input-Process-Product or CIPP Model examines its effects on the academic performance of foreign students. It looks into its course syllabi, goals and objectives, program content, strategies and methodologies, faculty profile and program duration, as these would arrest the competence and competitiveness of foreign students in the English language. In the assessment of foreign students, this study will determine if the English training programs pass William Dunn's four evaluation criteria, namely: effectiveness, responsiveness, appropriateness and adequacy.

Likewise, the researcher wants to find out, if there are significant positive changes in the level of the students' academic performance as a result of their training in ELPPFS course. The study makes use of quantitative-qualitative research consisting of survey questionnaires, structured interviews, taped conversations and ELPPFS files and documents. Aside from descriptive statistics like Mean, Percentage and Standard Deviation, it uses Inferential Statistics to determine whether or not there are significant changes in the level of academic performance as a result of their training in ELPPFS program. Our main findings are as below:

1). The prevailing conditions of foreign students enrolled in degree programs of UE Graduate School with respect to the level of their academic performance clearly show satisfactory evaluation marks. Generally, all 
these foreign students pursuing graduate studies in the university have completed English courses prior to admission in the graduate school. All foreign graduate entrants are required to take ELPPFS program with the exception of Indian students who have good command of English language. Other courses with TOEFL, IELTS, TWE and TSE designs and orientation are highly recommended for foreign students coming from non-English speaking countries to equip them with adequate proficiency in the English language.

2). ELPPFS program designed to improve academic performance of foreign students is successful. In terms of goals and objectives, program content, strategies and methods of instruction, faculty profile and program duration, ELPPFS intervention programs have been producing a maximum of satisfactory outcomes since its implementation past several years.

3). There is agreement among the three groups of respondents that ELPPFS programs pass the four of Dunn's evaluation criteria, as indicated in the following Mean scores: Effectiveness 2.99, Responsiveness 2.92, Appropriateness 2.94, and Adequacy 2.89.

4). There are significant positive changes in the academic performance of the three groups of respondents as a result of their ELPPFS training. In the same assessment by the three groups of respondents to ELPPFS programs of studies, namely: Group A - Iranians, Group B - Chinese, and Group C - Mixed Group, the researcher finds positive changes in the level of their academic performance as a result of their training in the ELPPFS. Statistics reveal that Group C indicates a high level of improved academic performance with a total Mean rating of 3.28, while Group B of Chinese respondents comes close to second with a total rating of 2.82. Group A of the Iranian students has 2.20 to rank the last. These statistics indicate that the three respondent groups show significant positive changes in their academic performance after they have attended and passed ELPPFS course.

\section{References}

Beretta, A. Toward A Methodology of English as a Second Language' (ESL) Program Evaluation. Teaching of English to Speakers of Other Languages. (TESOL) Quarterly, 20, 144-155.

Boulmettis, J. (1960). The ABC's of program evaluation: Timeless techniques for program and project managers. New York: Rinehart and Winston Publishing.

Buckney, C. (1985). Evaluating program to increase student achievement. New Jersey: Prentice Hall.

Isaac, S., \& William, M. (2000). Handbook in research and evaluation: Methods and strategies used in the planning, design and Evaluation of Studies in Education. New York: Prentice Hall.

Lardizabal, A. (1988). Foundations of education. Manila: Rex Publishing House.

Sanders, J. (1989). Evaluating school Programs: An Educator's guide. California: Sage Publishing House.

Smith, J. R. (1988). The Evaluator and Researcher as a Person Versus Person as Evaluator and Researcher. Educational Researcher, 17, 18-23. http://dx.doi.org/10.3102/0013189X017002018

Stake, R. E. (1985). Evaluating ediucational programmes: The Needs and responses. USA: Oxford University Press.

Stufflebean, D., \& Shinkfield, A. (1985). Evaluation theory: Models and Applications. California: Sage Newbury Park.

Weiss, C. H. (1985). Evaluation Research: Methods for assessing program effectiveness. New Jersey: Prentice Hall.

\section{Copyrights}

Copyright for this article is retained by the author(s), with first publication rights granted to the journal.

This is an open-access article distributed under the terms and conditions of the Creative Commons Attribution license (http://creativecommons.org/licenses/by/3.0/). 